\title{
Asthma, chronic obstructive pulmonary disease, or both? Diagnostic labeling and spirometry in primary care patients aged 40 years or more
}

This article was published in the following Dove Press journal: International Journal of COPD

16 November 2011

Number of times this article has been viewed

Hasse Melbye'

Elin Drivenes'

Lene G Dalbak ${ }^{2}$

Tone Leinan'

Svein Høegh-Henrichsen ${ }^{2}$

Anders $\varnothing$ strem $^{2}$

'General Practice Research Unit, Department of Community Medicine, University of Tromsø, ${ }^{2} \mathrm{General}$ Practice Research Unit, Department of Health and Society, University of Oslo, Norway
Correspondence: Hasse Melbye General Practice Research Unit, Department of Community Medicine, University of Tromsø, 9037 Tromsø, Norway

Tel +4777644816

Fax +4777644831

Email hasse.melbye@uit.no
Aims: To describe symptoms and lung function in patients registered with asthma or chronic obstructive pulmonary disease (COPD) in primary care and to examine how spirometry findings fit with general practitioners' (GPs) diagnoses.

Methods: Patients aged $\geq 40$ years with a diagnosis of asthma or COPD registered in the electronic medical record during the previous 5 years were recruited at seven GP offices in Norway in 2009-2010. Registered diagnosis, spirometry results, comorbidity, and reported symptoms were compared.

Results: Among 376 patients, 62\% were women. Based on Global Initiative for Chronic Obstructive Lung Diseases criteria, a spirometry diagnosis of COPD could be made in $68.1 \%$ of the patients with a previous COPD diagnosis and in $17.1 \%$ of those diagnosed with asthma only $(\mathrm{P}<0.001)$. The $\kappa$ agreement between last clinical diagnosis of COPD and COPD based on spirometry was 0.50 . A restrictive spirometry pattern was found in $19.4 \%$ and more frequently in patients diagnosed with both asthma and COPD $(23.9 \%)$ than in patients diagnosed with COPD only $(6.8 \%, P=0.003)$.

Conclusion: The ability of GPs to differentiate between asthma and COPD seems to have considerably improved during the last decade, probably due to the dissemination of spirometry and guidelines for COPD diagnosis. A diagnosis of COPD that cannot be confirmed by spirometry represents a challenge in clinical practice, in particular when a restrictive pattern on spirometry is found.

Keywords: asthma, COPD, diagnosis, primary care

\section{Introduction}

The prevalence of self-reported current asthma was $4.5 \%$ in a population-based survey among adults in the USA. ${ }^{1}$ The prevalence of chronic obstructive pulmonary disease (COPD) among those aged 40 years or older has been estimated to be $5 \%-10 \%{ }^{2}$ Considerably higher figures have been found based on spirometry in epidemiologic surveys $^{3}$ than in registrations from medical records. ${ }^{4,5}$ In a random sample of middleaged and elderly subjects from Norway, 3\% received medical treatment for COPD during 1 year. ${ }^{6}$ However, these $3 \%$ only accounted for one-third of those in the sample with spirometry findings indicating COPD according to the Global Initiative for Chronic Obstructive Lung Diseases (GOLD) guidelines. ${ }^{7}$ Medicine for either asthma or COPD was dispensed to $8 \%$ of Norwegians in $2004 .^{8}$

Between 1995 and 2004, the yearly registration of COPD in primary care medical records increased among men aged $\geq 65$ years from $1.5 \%$ to $5.0 \%$. At the same time, the registration of asthma dropped from $3.2 \%$ to $1.9 \%$ in the same group. ${ }^{9}$ This was explained 
by a change in the use of diagnostic labels, based on increased use of spirometry ${ }^{10}$ and new diagnostic guidelines. ${ }^{9}$ A similar shift in diagnostic labeling was clearly demonstrated in a large survey of British patients with obstructive lung disease from 1997 to 2000. Among the patients with a previous diagnosis of asthma, $56 \%$ had their diagnosis changed to COPD or a combination of the two diseases after being assessed by spirometry. ${ }^{11}$ Tinkelman et al $^{12}$ also described considerable discrepancy between diagnosis and spirometry results in a paper published in 2006, where approximately half of the patients with COPD according to the GOLD criteria were diagnosed with asthma.

This is the first presentation of a Norwegian study from general practice on asthma and COPD, DIOLUP (Better Diagnosis and Treatment in Exacerbations of Obstructive Lung Diseases in Primary Care). The aim of this study was to describe lung function, symptoms during the stable phase of illness, and diagnostic label used in men and women aged $\geq 40$ years. The investigators wanted to evaluate how appropriately the diagnostic labels of asthma and COPD are used, and explore features of patients who had been registered with both diagnoses in the medical record the preceding 5 years.

\section{Methods}

The study was carried out at seven general practice offices in the north and south of Norway. The practices were not randomly selected but were chosen based on availability of spirometry during the previous 5 years and the kind of electronic medical record used. Out of 43,241 subjects listed at these seven offices, 18,931 (43.8\%) were aged $\geq 40$ years. Among these, patients with a diagnosis of asthma or COPD who had been registered in the 5 years previous to the start of the study were identified. From these, a random sample of patients, following in alphabetical order, were invited by mail to take part. The number invited in each practice was decided based on the workload associated with and including each patient, as well as the capacity for such tasks at each office. Participation implied a baseline examination, including spirometry, during a stable phase of disease and, though not dealt with in this study, examinations during exacerbations the following 12 months. The baseline examinations took place between April 2009 and March 2010. The participants were told not to take their regular respiratory medication on the examination day.

\section{Registrations}

Prior diagnosis of asthma or COPD recorded by a general practitioner (GP) in the electronic medical records during the 5 years before the baseline examination was automatically registered by a software developed by Mediata AS (Tønsberg, Norway). Comorbidities were registered by GPs on a computerized questionnaire on the same platform and linked to the medical record. The patients registered smoking and coughing on a separate questionnaire, and questions on respiratory symptoms and quality of life items, including shortness of breath, on the Clinical COPD Questionnaire, a validated questionnaire. ${ }^{13}$ Height and weight were measured in some patients and were selfreported in others.

\section{Spirometry}

Spirometry was carried out by trained health workers, following European Respiratory Society/American Thoracic Society guidelines, ${ }^{14}$ using a Spirare SPS310 spirometer (Diagnostica AS, Oslo, Norway). The patients were seated, and a nose clip was not used. Postbronchodilator spirometry was carried out 20 minutes after inhalation of $0.4 \mathrm{mg}$ salbutamol, and a $12 \%$ increase of forced expiratory volume in the first second of expiration $\left(\mathrm{FEV}_{1}\right)$, together with a minimum increase of $200 \mathrm{~mL}$, was used as evidence of reversibility. The postbronchodilator $\mathrm{FEV}_{1}$ and forced vital capacity (FVC) were used in the analyses, and the patients with a $\mathrm{FEV}_{1} / \mathrm{FVC}$ ratio $<0.7$ were classified as $\mathrm{COPD}$ patients according to GOLD guidelines. In this cohort of patients diagnosed with asthma or COPD, asthma was the only possible diagnosis when $\mathrm{FEV}_{1} / \mathrm{FVC} \geq 0.7$, but it could be regarded as certain only when supported by a positive reversibility test. Norwegian reference values for spirometry were applied. ${ }^{15}$

\section{Statistical analyses}

Patients were grouped by diagnoses of asthma and COPD registered by the GPs in the medical record prior to the examination and by spirometry results following GOLD criteria. ${ }^{7}$ Patients with GOLD 3 and GOLD 4 spirometry $\left(\mathrm{FEV}_{1}<50 \%\right.$ predicted and $\mathrm{FEV}_{1} / \mathrm{FVC}$ ratio $\left.<70 \%\right)$ were grouped together, whereas patients with spirometry incompatible with COPD according to GOLD guidelines $\left(\mathrm{FEV}_{1} /\right.$ FVC ratio $\geq 70 \%$ ) were classified as "restrictive" when both $\mathrm{FEV}_{1} \%$ predicted and $\mathrm{FVC} \%$ predicted were $<80 \%{ }^{16}$ Differences among subgroups were analysed by $\chi^{2}$ test and Student's $t$-test. Agreement in diagnosis was assessed by $\kappa$ statistics. SPSS (v 17.0; SPSS, Inc, Chicago, IL) was used in the statistical analyses. A 5\% level of statistical significance was used. The study was approved by the Regional Committee for Medical and Health Research Ethics in North Norway. 


\section{Results}

Among the 18,931 patients aged $\geq 40$ years listed at the seven practices, 1784 (9.4\%) had been registered with a diagnosis of asthma or COPD during the previous 5 years (the background population, Table 1). A random sample of these, 1111, were invited, and 380 (34.2\%) accepted and took part in the baseline examination. In two patients, the GP prescribed antibiotics due to symptoms and signs of an acute exacerbation, and these were excluded from the analysis. Also excluded were two patients who did not perform postbronchodilator spirometry. Among the 376 remaining patients, $62.0 \%$ were women, and the median age was 62 years. The corresponding figures in the background population were $60.8 \%$ and 61 years (Table 1).

\section{Diagnosis}

A diagnosis of asthma had been made during the 5 years before baseline in $80.3 \%$ and a diagnosis of COPD in $44.1 \%$. COPD was most recently registered in 128 patients (34\%) and in $58(63 \%)$ of the subgroup with both diagnoses, among whom eight patients had been registered with both diagnoses the same day. Patients diagnosed with asthma only were younger (mean age 57.4 years) than those registered with COPD (66.7 years, $P<0.001$ ). A single diagnosis of COPD was registered more frequently in the background population than in the study sample, whereas the opposite was the case for the registration of both asthma and COPD (Table 1).

\section{Spirometry}

Postbronchodilator spirometry indicating COPD ( $\mathrm{FEV}_{1} /$ FVC < 0.7) was found in 149 patients $(39.6 \%)$, in 69 men (48.3\%) and 80 women (34.3\%) $(P=0.007)$. Before taking a

Table I Gender, age, and diagnosis in the study population of 376 patients and in the background population of $178 \mathrm{I}$ patients aged $\geq 40$ years diagnosed with asthma or chronic obstructive pulmonary disease (COPD) in primary care

\begin{tabular}{lll}
\hline & $\begin{array}{l}\text { Study } \\
\text { population } \\
\mathbf{n = 3 7 6}(\%)\end{array}$ & $\begin{array}{l}\text { Background } \\
\text { population } \\
\mathbf{n}=\mathbf{I 7 8} \text { I (\%) }\end{array}$ \\
\hline Women & $233(62.0)$ & $1083(60.8)$ \\
Men & $143(38.0)$ & $698(39.2)$ \\
Age (years, median) & 62 & 61 \\
Diagnostic category & & \\
Asthma & $302(80.3)$ & $1298(72.9)$ \\
COPD & $166(44.1)$ & $720(40.4)$ \\
Asthma, no COPD & $210(55.9)$ & $1061(59.6)$ \\
COPD, no asthma & $74(19.7)$ & $237(27.1)^{\mathrm{a}}$ \\
Both asthma and COPD & $92(24.5)$ & (13.3)
\end{tabular}

Note: ${ }^{\text {TT }}$ The difference in frequency between study sample and the nonparticipating part of the background population is statistically significant, $P<0.00 \mathrm{I}$. bronchodilator there were 157 patients with $\mathrm{FEV}_{1} / \mathrm{FVC}<0.7$. Reversibility was detected in $16.8 \%$. Of the patients, $95.5 \%$ expired for 6 seconds or more when performing postbronchodilator spirometry. A spirometry diagnosis of COPD could be made in $68.1 \%$ of the patients with a previous COPD diagnosis and in $17.1 \%$ of those diagnosed with asthma only $(P<0.001)$. GOLD $3-4$ spirometry was found $13 \times$ more frequently among the patients diagnosed with COPD only or with both diagnoses than among those diagnosed with asthma only (Table 2). A restrictive pattern was found in $19.4 \%$ of the patients, and more than three times as frequently in the patients diagnosed with both asthma and COPD than in the COPD-only group, and with similar frequency as in the asthma-only group (Table 2).

\section{Agreement between clinical diagnosis and spirometry}

Of the 149 patients with $\mathrm{FEV}_{1} / \mathrm{FVC}<0.7$, COPD was registered in $75.3 \%$ and was the latest diagnosis given in $63.8 \%$. Conversely, COPD, as the latest diagnosis, was confirmed by spirometry in $74.2 \%$. The $\kappa$ agreement between the COPD as the latest diagnosis in the medical record and COPD diagnosis based on spirometry was 0.50 (Table 3).

\section{Smoking and comorbidities}

The patients with a diagnosis of asthma only were more frequently never smokers and less frequently previous smokers compared with the patients diagnosed with COPD (Table 4).

Table 2 Age and lung function by diagnosis registered in the medical record in 376 patients aged $\geq 40$ years diagnosed with asthma or chronic obstructive pulmonary disease (COPD) in primary care

\begin{tabular}{llll}
\hline & $\begin{array}{l}\text { Asthma only } \\
\mathbf{n = 2 1 0}(\%)\end{array}$ & $\begin{array}{l}\text { COPD only } \\
\mathbf{n = 7 4}(\%)\end{array}$ & $\begin{array}{l}\text { Both asthma } \\
\text { and COPD } \\
\mathbf{n}=\mathbf{9 2}(\%)\end{array}$ \\
\hline $\begin{array}{l}\text { Age } \geq 65 \text { years } \\
\text { Spirometry }\end{array}$ & $26.7^{\mathrm{a}}$ & 62.2 & 54.3 \\
Normal $(\mathrm{n}=154)$ & $61.0^{\mathrm{a}}$ & 13.5 & 17.4 \\
Restrictive $(\mathrm{n}=73)$ & 21.9 & $6.8^{\mathrm{c}}$ & 23.9 \\
GOLD I $(\mathrm{n}=18)$ & $2.4^{\mathrm{b}}$ & 14.9 & 2.2 \\
GOLD 2 $(\mathrm{n}=87)$ & $12.9^{\mathrm{a}}$ & 33.8 & 38.0 \\
GOLD 3-4 $(\mathrm{n}=44)$ & $1.9^{\mathrm{a}}$ & 31.1 & 18.5 \\
Reversibility $(\geq 12 \%$ & 14.3 & 17.6 & 21.7 \\
and $>0.2 \mathrm{~L}, \mathrm{n}=63)$ & & & \\
\hline Notes The & & & \\
\hline
\end{tabular}

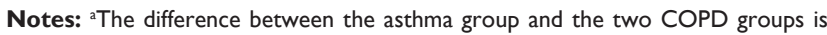
statistically significant, $P<0.00 \mathrm{I}$; bthe difference between the asthma group and the two COPD groups is statistically significant, $P=0.01$; ' the difference between the two COPD groups is statistically significant, $P=0.003$.

Abbreviation: GOLD, Global Initiative for Chronic Obstructive Lung Diseases. 
Table 3 Agreement between chronic obstructive pulmonary disease (COPD) as the diagnosis most recently registered in the medical record before the examination, and the diagnosis indicated by spirometry in 376 patients aged 40 years or more diagnosed with asthma or COPD in primary care ( $\kappa 0.50$ [standard deviation 0.05 ])

\begin{tabular}{llll}
\hline & \multicolumn{3}{c}{ COPD according to spirometry } \\
\cline { 2 - 4 } & Yes & No & Total \\
\hline COPD registered in medical record & & 33 & 128 \\
Yes & 95 & 194 & 248 \\
No & 54 & 227 & 376 \\
Total & 149 &
\end{tabular}

Diabetes, hypertension, atopic eczema, and allergic rhinitis were more common among the patients with both diagnoses than in those with a single diagnosis of COPD (Table 4). Obesity (body mass index $\geq 30$ ) was found in $47.1 \%$ in the restrictive group significantly more frequently $(P<0.001)$ than among the patients with obstructive $\left(\mathrm{FEV}_{1} / \mathrm{FVC}<0.7\right)$

Table 4 Smoking, comorbidity, and coughing by diagnosis registered in the medical record previous to the study in 376 patients aged $\geq 40$ years diagnosed with asthma or chronic obstructive pulmonary disease (COPD) in primary care

\begin{tabular}{|c|c|c|c|}
\hline & $\begin{array}{l}\text { Asthma } \\
\text { only } \\
n=210 \text { (\%) }\end{array}$ & $\begin{array}{l}\text { COPD } \\
\text { only } \\
n=74(\%)\end{array}$ & $\begin{array}{l}\text { Both asthma } \\
\text { and COPD } \\
n=92(\%)\end{array}$ \\
\hline \multicolumn{4}{|l|}{ Smoking habit } \\
\hline $\begin{array}{l}\text { Current smoker } \\
(\mathrm{n}=103)\end{array}$ & 23.8 & 27.0 & 35.9 \\
\hline $\begin{array}{l}\text { Previous smoker } \\
(\mathrm{n}=162)\end{array}$ & $36.7^{\mathrm{a}}$ & 55.4 & 47.8 \\
\hline $\begin{array}{l}\text { Never smoker } \\
(\mathrm{n}=\mathrm{III})\end{array}$ & $39.5^{\mathrm{b}}$ & 17.6 & 16.3 \\
\hline \multicolumn{4}{|l|}{ Comorbidity } \\
\hline $\begin{array}{l}\text { Obesity (body } \\
\text { mass index } \geq 30 \text { ) }\end{array}$ & 25.4 & 15.9 & 27.1 \\
\hline $\begin{array}{l}\text { Cardiovascular } \\
\text { disease }(n=122)\end{array}$ & $22.9^{\mathrm{b}}$ & 51.4 & 39.1 \\
\hline Diabetes $(n=3 \mid)$ & 4.8 & 5.4 & $18.5^{c}$ \\
\hline $\begin{array}{l}\text { On antihypertensives } \\
(n=138)\end{array}$ & 30.0 & 36.5 & $52.2^{\mathrm{c}}$ \\
\hline $\begin{array}{l}\text { Atopic eczema } \\
(\mathrm{n}=56)\end{array}$ & 19.0 & 4.1 & $14.1^{c}$ \\
\hline $\begin{array}{l}\text { Allergic rhinitis } \\
(n=I 55)\end{array}$ & 53.8 & 17.6 & $31.5^{c}$ \\
\hline \multicolumn{4}{|l|}{ Cough } \\
\hline Usually not $(\mathrm{n}=117)$ & 32.0 & 36.1 & 26.4 \\
\hline Usually dry $(n=92)$ & 26.7 & 25.0 & 20.9 \\
\hline $\begin{array}{l}\text { Usually with phlegm } \\
(n=161)\end{array}$ & 41.3 & 38.9 & 52.7 \\
\hline
\end{tabular}

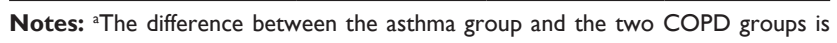
statistically significant, $P=0.005$; ${ }^{b}$ the difference between the asthma group and the two COPD groups is statistically significant, $P<0.001$; ' the difference between the two COPD groups is statistically significant, $P<0.05$; ' weight was registered in only 355 patients. or normal spirometry, who had frequencies of $13.2 \%$ and $22.8 \%$, respectively.

\section{Symptoms}

There were only minor differences in reported coughing and phlegm between the three diagnostic groups (Table 4). Shortness of breath during physical activity was the symptom most frequently reported, according to the registrations on the Clinical COPD Questionnaire $-51 \%$ had this symptom several times or more in the last week. Shortness of breath during physical activity "a great many times" or "almost all of the time" was reported by $18.6 \%$ and more frequently in the GOLD 3-4 group than in the other spirometry groups $(P<0001$, Figure 1). Such severe shortness of breath was reported significantly more frequently by the patients who had been diagnosed with COPD compared with those with a single diagnosis of asthma $(P<0.001$, Figure 1$)$.

\section{Discussion}

\section{The accuracy of the COPD diagnosis}

The registration of COPD in $64 \%$ of the patients with $\mathrm{FEV}_{1} /$ FVC $<0.7$ represents an improvement in detection of COPD in routine care compared with previous studies. ${ }^{11,12,17}$ In a similar study by Tinkelman et al, ${ }^{12}$ the corresponding detection rate was $42.9 \%$. In the present study, $17.1 \%$ of the patients diagnosed with asthma only had COPD according to spirometry, whereas in the CADRE (COPD and Asthma Diagnostic/Management Reassessment) study, ${ }^{11} 56 \%$ of asthma patients could be labeled with a COPD diagnosis after spirometry. Overdiagnosis of COPD was a smaller problem in the present study than in previous studies. Of the 128 patients who had been diagnosed with COPD the last time asthma or COPD was registered in the medical records, diagnosis was confirmed by spirometry in $74.2 \%$, whereas the frequency was $48.4 \%$ in Tinkelman et al's ${ }^{12}$ study. This improvement in diagnostic accuracy is not surprising, taking into account the strong increase in the use of spirometry in primary care ${ }^{9,10}$ and the dissemination of diagnostic guidelines promoted by, among others, the GOLD initiative. But this improvement should not be ascribed to the GPs alone. Many patients have consulted pulmonologists and had their diagnosis adjusted by them. In the present study, a $\kappa$ agreement of 0.50 was found, which is characterized as "moderate" by Altman. ${ }^{18}$ Although a further decrease in misdiagnosis should be pursued, a complete agreement is probably neither possible nor wanted. The GOLD criteria for diagnosing COPD should be regarded as a guide and not as a strict rule. ${ }^{19,20}$ The high frequency of previous smoking, 


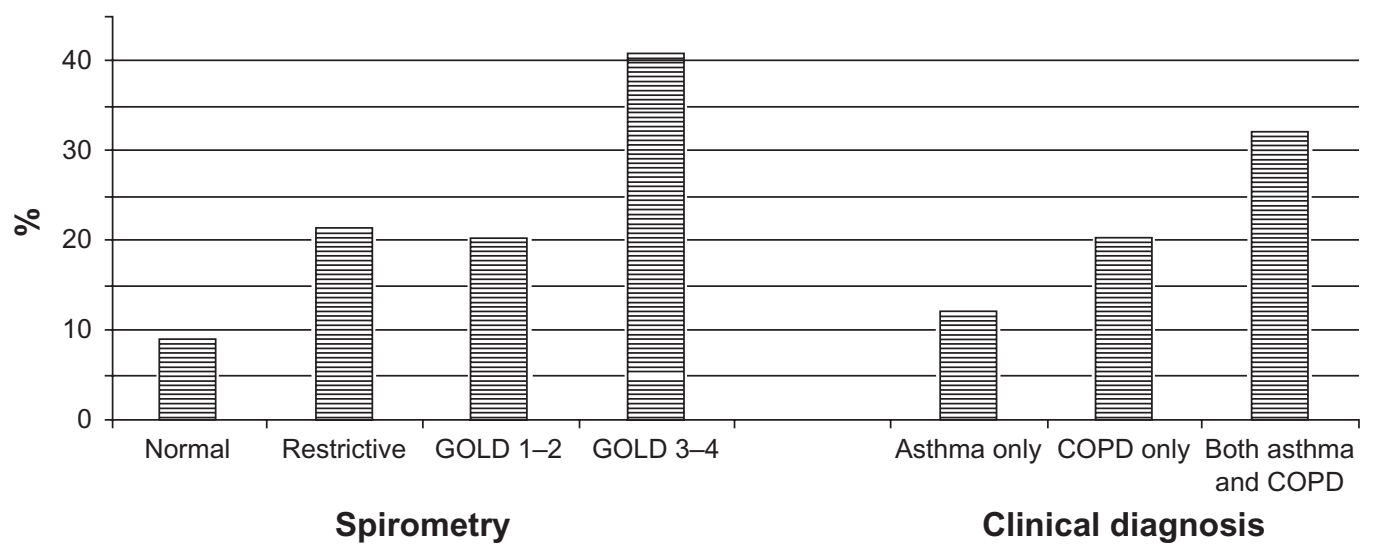

Figure I Frequency of reporting shortness of breath occurring either a great many times or almost all the time the week before the examination in 37 I patients aged $\geq 40$ years diagnosed with asthma or chronic obstructive pulmonary disease (COPD) in primary care. Abbreviation: GOLD, Global Initiative for Chronic Obstructive Lung Diseases.

cardiovascular disease, and current shortness of breath (Table 4, Figure 1) in the patients labeled with COPD may indicate a substantial impact of presenting symptoms and clinical history in the diagnostic work-up.

\section{Mixed diagnosis}

Among the patients who had been registered with both asthma and COPD during the previous 5 years, COPD was more frequently the last diagnosis of the two. This probably represents the trend of change in diagnosis from asthma to COPD.

There may also be other reasons for alternating between the diagnoses of asthma and COPD. Asthma, recognized or unrecognized in the health care system, may develop into COPD.$^{21}$ This may, for instance, happen when an asthmatic keeps on smoking. A real presence of both diseases is supported by the relatively high frequency of atopic eczema and allergic rhinitis in the subgroup with both diagnoses. A tendency to prefer the use of an asthma diagnosis may have been strengthened by the reimbursement regulation for respiratory medication introduced in Norway in 2006. When the study was carried out, costs of inhaled corticosteroids and inhaled corticosteroids combined with long-acting $\beta_{2}$-agonists could be reimbursed, as a rule, only in patients with a diagnosis of asthma.

A third possible explanation to the use of both diagnoses may be related to the GPs' difficulties in deciding on a diagnosis. Many patients with mixed diagnosis were obese and suffered from diabetes. Obesity and metabolic syndrome are frequently associated with pulmonary restriction, ${ }^{22}$ which was a common finding in the authors' patients with mixed diagnosis. A restrictive pattern on the spirogram may also be found in congestive heart failure. ${ }^{23}$ When assessing patients with shortness of breath, a restrictive pattern on spirometry may indicate obesity or heart failure, instead of asthma or COPD. However, a restrictive pattern may also be seen in emphysema, when the residual volume is considerably increased, and due to hyperinflation in insufficiently controlled asthma and COPD patients. ${ }^{24,25}$ It has also been reported in asthma patients in whom obesity, heart failure, and hyperinflation have been ruled out. ${ }^{26}$

In this study, the patients were seated, as recommended, ${ }^{16}$ during spirometry. This practice may reduce the FVC in obese people. ${ }^{27}$ Perhaps some of the obese patients with restrictive spirometry could have been diagnosed as obstructive if the procedure had been carried out standing.

Mixed diagnosis may also reflect frequent visits to the practice and consultations with more than one doctor during the 5-year period.

\section{Asthma}

Asthma was the diagnosis most frequently registered in the medical record. Patients diagnosed with asthma and not COPD had better lung function and were less bothered by shortness of breath than patients diagnosed with COPD. This could be expected due to the episodic character of the disease and the efficacy of medical treatment. ${ }^{28}$ The high frequency of allergic rhinitis $(53.8 \%$, Table 4$)$ indicates the impact of comorbidity when a diagnosis of asthma is made. ${ }^{29}$ Severe COPD (GOLD 3-4 spirometry) was very infrequent in the subgroup with only asthma diagnosis (1.9\%), whereas $15.2 \%$ had mild to moderate COPD. Accordingly, spirograms obtained during the 5 years before the study could probably support a diagnosis of asthma in the great majority of cases. In this study, reversibility testing supported a diagnosis of asthma in only $14.3 \%$. However, a positive reversibility 
test can be expected only in asthma patients who are not adequately treated. ${ }^{28}$

\section{Strengths and weaknesses}

This was a prospective study carried out at dedicated GP offices. Missing data have been a minor problem, but the quality of the spirometry has probably been better than usual. Because the participation rate of the patients invited to the study was only $34 \%$, it cannot be assumed that the study sample is representative of the background population. Patients who had been given a diagnosis of both asthma and COPD participated much more frequently than those with a single diagnosis of COPD. A double diagnosis may, as mentioned previously, reflect frequent visits to the practice and, accordingly, a more severe illness, also indicated by the high frequency of dyspnea in this subgroup (Figure 1). The low participation rate among those with a single diagnosis of COPD may reflect that the most severely impaired COPD patients, who are frequently hospitalized and followed up in secondary care, were less inclined to participate. At the other end of the spectrum, patients who had once had a diagnosis of asthma or COPD but now felt generally healthy might also have been less interested in taking part and could thus be underrepresented. However, the selection biases have probably had little influence on the main findings of the study in terms of associations among diagnostic labels, spirometry results, and symptoms.

Although the participants were told to meet for the baseline examination during a stable phase of their disease, some patients were probably not optimally treated. This may have led to overdiagnosis of COPD in some cases, for instance, among patients who, in reality, suffered from asthma. Unsatisfactory performance of spirometry may also have had some impact on the results. Although $95.5 \%$ of the patients expired for more than 6 seconds, a too-low FVC was probably attained in some patients. This may have led to misclassification of some COPD patients into the normal and restrictive groups.

The GP offices chose voluntarily to take part in the study and might not be representative of Norwegian practices. In 3/7 offices, the participating GPs had a special interest in spirometry and obstructive lung diseases. However, the $\kappa$ agreement between clinical diagnosis and spirometry based on these three offices was similar (0.48) to that found in the other four offices $(0.52)$.

\section{Implications for clinical practice}

GPs' capability of detecting COPD is improving, thanks to the dissemination of spirometry and GOLD guidelines in primary care. The focus on diagnosing COPD should still be strong, due to the evident effect of quitting smoking for this disease. ${ }^{7}$ However, it should be acknowledged that some patients suffer from both asthma and COPD, and that spirometry does not differentiate between asthma and COPD in all cases. Detection of a restrictive spirometry pattern may represent a particular challenge, and clinicians should probably consider other explanations for shortness of breath than asthma and COPD, including obesity, when a restrictive pattern is found.

\section{Acknowledgments}

The project was supported with a grant to ED and LGD from the Fund for General Practice Research within the Norwegian Medical Association. LGD, SHS, and AØ were supported with unrestricted grants from MSD (Norway) AS, GlaxoSmithKline AS, and AstraZeneca AS. TL was supported by a grant from the Research Program of the National Centre for Rural Medicine. The authors thank the participating patients and Nordbyen legesenter, Tromsø, Allmed legesenter, Hammerfest, Alta helsesenter, Skedsmokorset legesenter, Lillestrøm legesenter, Langbølgen legesenter, Oslo, and Gransdalen legesenter, Oslo, for their participation in collecting data.

\section{Disclosure}

AØ has lectured on behalf of, received sponsorship from, or provided consultancy services to Boehringer Ingelheim, Pfizer, GSK, and Nycomed. SHS has participated in studies financed by Boehringer Ingelheim and AZ, and lectured on behalf of Pfizer, GSK, and Nycomed.

\section{References}

1. Arif AA, Delclos GL, Lee ES, et al. Prevalence and risk factors of asthma and wheezing among US adults: an analysis of the NHANES III data. Eur Respir J. 2003;21:827-833.

2. Mannino DM, Buist AS. Global burden of COPD: risk factors, prevalence, and future trends. Lancet. 2007;370:765-773.

3. Buist AS, McBurnie MA, Vollmer WM, et al. International variation in the prevalence of COPD (the BOLD Study): a population-based prevalence study. Lancet. 2007;370:741-750.

4. White P. Prevalence of COPD in primary care: no room for complacency. Fam Pract. 2009;26:1-2.

5. Mohangoo AD, van der Linden MW, Schellevis FG, Raat H. Prevalence estimates of asthma or COPD from a health interview survey and from general practitioner registration: what's the difference? Eur J Public Health. 2006;16:101-105.

6. Hvidsten SC, Storesund L, Wentzel-Larsen T, et al. Prevalence and predictors of undiagnosed chronic obstructive pulmonary disease in a Norwegian adult general population. Clin Respir J. 2010;4:13-21.

7. Rabe KF, Hurd S, Anzueto A, et al. Global strategy for the diagnosis, management, and prevention of chronic obstructive pulmonary disease: GOLD executive summary. Am J Respir Crit Care Med. 2007;176: $532-555$. 
8. Selstad GM, Melbye H. Oral corticosteroids for asthma or COPD were dispensed to $2.6 \%$ of Norwegians aged 7 years or over in 2004-2005. Prim Care Respir J. 2011;20:332-333.

9. Haugan T, Bakken IJ, Storro O, et al. Utilization of diagnostic tools and health care services for obstructive lung disease. Tidsskr Nor Laegeforen. 2008;128:2431-2434.

10. Joensen L, Melbye H. Spirometry in general practice in Northern Norway. Tidsskr Nor Laegeforen. 2010;130:33-35. Norwegian.

11. Pearson M, Ayres JG, Sarno M, et al. Diagnosis of airway obstruction in primary care in the UK: the CADRE (COPD and Asthma Diagnostic/ management REassessment) programme 1997-2001. Int J Chron Obstruct Pulmon Dis. 2006;1:435-443.

12. Tinkelman DG, Price DB, Nordyke RJ, Halbert RJ. Misdiagnosis of COPD and asthma in primary care patients 40 years of age and over. J Asthma. 2006;43:75-80.

13. van der Molen T, Willemse BW, Schokker S, et al. Development, validity and responsiveness of the Clinical COPD Questionnaire. Health Qual Life Outcomes. 2003;1:13.

14. Miller MR, Hankinson J, Brusasco V, et al. Standardisation of spirometry. Eur Respir J. 2005;26:319-338.

15. Langhammer A, Johnsen R, Gulsvik A, et al. Forced spirometry reference values for Norwegian adults: the Bronchial Obstruction in Nord-Trondelag Study. Eur Respir J. 2001;18:770-779.

16. Global Initiative for Chronic Obstructive Lung Disease (GOLD). Spirometry for health care providers. Available from: http://www. gpcme.co.nz/pdf/GOLD\%20SpirometryFull\%5B1\%5D.pdf. Accessed October 11, 2011.

17. Walker PP, Mitchell P, Diamantea F, et al. Effect of primary-care spirometry on the diagnosis and management of COPD. Eur Respir J. 2006;28:945-952.
18. Altman DG. Practical statistics for medical research. London: Chapman \& Hall, 10 A.D; 1997.

19. Medbo A, Melbye H. Lung function testing in the elderly: can we still use FEV(1)/FVC $<70 \%$ as a criterion of COPD? Respir Med. 2007;101: 1097-1105.

20. Schneider A, Gindner L, Tilemann L, et al. Diagnostic accuracy of spirometry in primary care. BMC Pulm Med. 2009;9:31.

21. Guerra S. Asthma and chronic obstructive pulmonary disease. Curr Opin Allergy Clin Immunol. 2009;9:409-416.

22. Rogliani P, Curradi G, Mura M, et al. Metabolic syndrome and risk of pulmonary involvement. Respir Med. 2010;104:47-51.

23. Light RW, George RB. Serial pulmonary function in patients with acute heart failure. Arch Intern Med. 1983;143:429-433.

24. O'Donnell DE, Laveneziana P. The clinical importance of dynamic lung hyperinflation in COPD. COPD. 2006;3:219-232.

25. Rothe T. True restrictive ventilatory pattern in asthma. J Asthma. 2010;47:594-596.

26. Miller A, Palecki A. Restrictive impairment in patients with asthma. Respir Med. 2007;101:272-276.

27. Gudmundsson G, Cerveny M, Shasby DM. Spirometric values in obese individuals. Effects of body position. Am J Respir Crit Care Med. 1997;156:998-999.

28. Bateman ED, Hurd SS, Barnes PJ, et al. Global strategy for asthma management and prevention: GINA executive summary. Eur Respir J. 2008;31:143-178.

29. Thomas M. Allergic rhinitis: evidence for impact on asthma. BMC Pulm Med. 2006;6:S4.
International Journal of COPD

\section{Publish your work in this journal}

The International Journal of COPD is an international, peer-reviewed journal of therapeutics and pharmacology focusing on concise rapid reporting of clinical studies and reviews in COPD. Special focus is given to the pathophysiological processes underlying the disease, intervention programs, patient focused education, and self management protocols.

\section{Dovepress}

This journal is indexed on PubMed Central, MedLine and CAS. The manuscript management system is completely online and includes a very quick and fair peer-review system, which is all easy to use. Visit http://www.dovepress.com/testimonials.php to read real quotes from published authors. 